\title{
East African running dominance: what is behind it?
}

Bruce Hamilton

\section{Introduction}

East African middle and long distance runners are currently the dominant force in athletics. As well as dominating the track events at the last several Olympic Games, they are also dominant on the American and European road racing circuit and world cross country events. Although many physiological and anatomical factors have been proposed to explain East African dominance, research into these variables has not yet revealed any definitive advantage for the African. Traditional social and cultural factors have often been described as "advantageous", and, although these factors may be to a greater or lesser extent involved in the East African dominance, it is probable that both the African and caucasian psychology or "mindset" are now additional important factors in maintaining that dominance. Like Scandinavian distance runners in the early 20 th century, who won 28 of 36 possible Olympic medals over 5000 and $10000 \mathrm{~m}$, the East Africans have developed an aura of invincibility, both in their own minds and the minds of their caucasian opponents. Caucasians world wide are searching for proof of the physical advantage of the East Africans while handing them on a platter a psychological advantage which, until removed, will perpetuate the current state.

\section{Possible reasons for East African dominance}

Many factors have been described to explain both the dominance of East African middle and long distance runners and West African sprinters. Many of these have been disproved many times but are so fixed in folklore that they continue to be touted as possible causes of success. Despite being shown to be unsubstantiated in the 1930s, ${ }^{1}$ Sir Roger Bannister, in a speech delivered to the British Association for the Advancement of Science in 1995, suggested that factors such as heel bone length, subcutaneous fat, and differences in Achilles tendon length may explain the advantages that West African athletes appear to have. ${ }^{12}$ Proposed factors involved in the success of East African athletes include environmental, genetic endowment, and social development, ${ }^{3}$ while the psychological make up of the East African is rarely considered.

ENVIRONMENTAL AND PHYSIOLOGICAL VARIABLES Environmental determinism is a term used to describe the attribution of human performance to the environment in which the human lives. Scandinavian running dominance in the early 20th century, easily comparable with that of East African dominance today, was felt to be a result of the forests, lakes, and scenery enhancing the performance of the athletes. ${ }^{4}$ In the case of the East African runner, it is widely believed that birth and living at altitude produces great athletes, despite the great range in athletic productivity observed between areas of similar altitude. $^{5}$ If altitude were the only factor involved, then all African countries with high altitude populations, as well as countries such as Nepal, Peru, and Mexico, should be producing many world class athletes. ${ }^{5}$ While studying the difference between muscle fibre types of highland and lowland Andean dwellers, Rosser and Hochachka ${ }^{6}$ found that type I (slow twitch) muscle fibres of those living at altitudes of $3300 \mathrm{~m}$ had reduced levels of oxidative enzymes (malate dehydrogenase) and enhanced glycolytic ability. Despite the small sample size (three), this may suggest that chronic exposure to altitude reduces rather than enhances maximal aerobic potential. ${ }^{6}$ Similarly, using analysis of indirect maximal oxygen uptake and muscle biopsies, Kayser et $a l^{l}$ compared five Nepalese Sherpas with caucasian climbers and lowland sedentary adults. They found the Sherpas to have significantly lower maximal aerobic uptake and lower mitochondrial density, but equivalent capillary density and muscle fibre size compared with acclimatised caucasian climbers. They concluded that the Sherpas' legendary endurance could not be explained by any of the features studied, which were found not to be unique to Sherpas. It could be argued that the variables measured do not reflect the key physiological parameters involved, and Noakes ${ }^{8}$ has theorised that cardiac function may well be the differentiating variable. Saltin et a ${ }^{\beta}$ found that Scandinavian athletes living at sea level had a higher muscle buffering capacity than Kenyan athletes, and that altitude training enhanced muscle buffering capacity in sea level residents training at altitude, but not in Kenyans who reside at altitude.

Hence, although it is clear that living and training at altitude results in a variety of physiological adaptations, the exact nature and relative importance of these adaptations to the success of athletes from altitude are yet to be elucidated. Legendary runner Ron Clarke highlighted this clearly in 1981, “ . . .record breaking in distance running has come from very small areas of the world ... New Zealand; Australia; England; a small part of the African continent . . .and maybe Finland. These countries have produced the record breakers and yet none of the areas are the same ... Why such a small area of the world has prolifically produced world record holders I don't know". 
Genetic endowment is often stated as an "obvious" cause of East African dominance. This is especially so when one considers the Kenyan experience. In 1988 the Nandi people in the Rift Valley (one of seven tribes making up a larger group known as Kalenjin), comprised $1.8 \%$ of Kenya's population but supplied $42.1 \%$ of the nation's elite runners. ${ }^{5}$ However, intermarrying between the different Kalenjin tribes has been occurring for many years ${ }^{10}$ suggesting that factors other than just the Nandi gene pool are involved. Physiological advantages of Africans have recently been studied in depth by Weston et al, ${ }^{11}$ comparing African subelite $10 \mathrm{~km}$ runners (eight from the Xhosa tribe, one from the Zulu tribe) with caucasians of similar ability. They found that the Africans had elevated citrate synthase and 3-hydroxyacyl-CoA dehydrogenase activity and enhanced resistance to fatigue in a treadmill trial designed to imitate the stresses involved in $10 \mathrm{~km}$ running. However, no correlation was found between these variables and the best $10 \mathrm{~km}$ run time, and the researchers acknowledge the importance of such factors as environmental conditions, nutrition, and motivation in racing performance. With particular regard to Kenyan runners, Saltin et al ${ }^{3}$ reported elevated 3-hydroxyacyl-CoA dehydrogenase but not citrate synthase activity, differences that Weston $e t a l^{11}$ suggest may be a result of the confounding effect of altitude exposure. In addition, Weston et $a l^{11}$ found African runners to have a lower percentage of type I muscle fibre, the fibre type that is typically associated with endurance performance. This is in contrast with the classical expectations of elite distance runners and the findings of others, ${ }^{12}$ but Weston et al account for this by suggesting that this is an appropriate adaptation for the increased speed and hence glycolytic demands of modern $10 \mathrm{~km}$ running. Hence, while Weston et al describe possible factors involved in the enhanced fatigue resistance as shown by a treadmill test, there are clearly other factors involved in the consistent racing success of African runners. Similarly, Coetzer et $a l^{12}$ compared elite South African caucasian and black athletes. They found that the black athletes trained more intensively and were able to sustain a higher percentage of their maximal oxygen consumption during competition. It was felt that this may have been related to the lower blood lactate concentrations found in black athletes at any given running speed. Although these findings may support an innate explanation for performance differences, it is possible that similar factors may also explain performance differences in racially homogeneous groups.

The degree to which findings from South African runners can be extrapolated to more northern tribes is another factor to consider, given that racial characteristics lack homogeneity even within so called racial groups. ${ }^{4}$ Finally, when examining the factors that separate the best from the merely elite, one must consider the rationale of extrapolating findings from subelite athletes.
Clearly innumerable physiological variables could be involved in the dominance of the East African athlete. However, at this stage, the exact nature of these variables and their relative importance, as well as the role of nature and nurture, are not clear.

SOCIAL VARIABLES

The British attitude to their own sporting prowess in the early 20th century and the relationship to training children and adolescents is reflected in an early text on athletic training. "We pride ourselves on being . . the first athletic nation. We have many assets that should make us so. Our public school games are, one and all, of incalculable help towards the many assets demanded in an international competition. By favour of these, the youngster, unknown to himself, is putting in his ground work, in conjunction with a national temperament that has, in the past pulled off big things. Pluck, patience, enterprise, equanimity in loss, restraint in victory, suppleness of limb, are all indirectly taught the schoolboy, and if he can be kept up to the mark set by all public schools, no more can, or should be, expected of him. He is undergoing the fullest training that any healthy lad should be subjected to". ${ }^{13}$

With the emerging East African athletic dominance, similar principles appear to have been applied. Years of running to and from school as children and adolescents has often been quoted as contributing to the development of elite East African runners. Indeed, Saltin et $a l^{10}$ describe their elite subjects as having run or walked an average of $8-12 \mathrm{~km}$ a day, five days a week from age 7-8 years, increasing to $90 \mathrm{~km}$ a week as adolescents. They also found that Kenyan children who did not have to walk great distances to school had maximal oxygen uptakes $30 \%$ lower than those required to travel to school by foot, and hence similar to that of Danish children. However, they also describe how Kenyan teenagers "out of training" had significantly lower maximal oxygen consumptions than students who had just begun regular training. Hence, this may in fact suggest that organised training plays a significant role in the development of high maximal oxygen consumption in Kenyan adolescents. Small samples and a lack of clarity about exactly what constitutes formal goal directed training make these findings difficult to interpret accurately. In comparison, Bale and Sang ${ }^{5}$ report that 14 of 20 elite Kenyan athletes interviewed never had been required to run to school. As long ago as 1960 when the great Kipchoge Keino appeared on the international scene, talented Kenyan runners were being removed from their homelands and being placed in protected employment to enable the full development of their running ability. With the increasing westernisation of Eastern Africa and the development of athletic programmes in schools, ${ }^{14}$ targeting the perceived Nandi potential, one must question the role of "natural training" in the development of elite athletes.

In comparison with the Nandi, who have remained a relatively rural society, many other 
Kenyan tribes have experienced accelerated urbanisation, with the resulting availability of alternative sports in cities reducing the pool of competitive runners. Hence, the rural environment and lack of resources for alternative sports is one of the factors involved in the maintenance of the Nandi dominance of Kenyan running.

Clearly, while the latest generation of East African athletes have a very different social development from those of the first half of this century, similar stereotypes continue to be applied. As has been illustrated, these stereotypes are based on factors that are no longer universally applicable.

\section{PSYCHOLOGICAL VARIABLES}

There is clearly more to the East African success story than their physiology, genetics, and childhood athletic endeavours. Regardless of physical attributes, the tougher athlete often prevails and the difference between success and failure is often more easily, and perhaps more appropriately, attributed to factors such as psychology. ${ }^{15}$ Psychologically, performance can be considered to be a function of the interaction between a person and the environment, or, by extension, the interaction of intrapersonal and interpersonal factors. Intrapersonal factors such as belief in oneself, motivation, achievement orientation are critical to performance. Berg-Schlosser (cited by Bale and Sang $^{5}$ ) disclosed in the 1970s that, of all the Kenyan tribes, the Kalenjin had the highest achievement orientation, while Mahlmann ${ }^{16}$ more recently found that the Kalenjin had the greatest ascetic experience of sport, both factors considered to be important in the successful performance of individual sports.

Attitudes may be defined as "relatively stable, individual difference characteristics that presumably (sic) predispose the individual to certain behaviours", ${ }^{17}$ and which tend to be directed towards specific objects, people, or ideas. Festinger's theory of cognitive dissonance (cited by Gill $^{17}$ ) may provide some insight into the development of attitudes to East African runners by caucasians. This theory suggests that people like to be consistent in their thoughts, attitudes, opinions, and behaviours. Hence, if one considers that there is no advantage in being an East African in terms of athletic performance, and yet is consistently confronted with caucasian defeats, cognitive dissonance is created. To reduce this dissonance, either caucasian results must improve or beliefs about the advantages of being African must change. Clearly if the latter occurs, a belief structure is set in place that will aid only the East African.

Triandis (cited by Gill $^{17}$ ) described three components to attitudes:

(1) cognitive-reflecting beliefs, or knowledge, on a given subject, object, or person;

(2) affective-positive or negative feelings towards a subject, object, or person;

(3) behavioural - the intended behaviour towards the subject, object, or person.

Hence, from a caucasian point of view, a person's cognitive understanding of a group such as East African runners, although not directly predicting behaviour, when combined with other factors such as social situation will certainly influence the person's behavioural pattern. If therefore a person believes that Kenyan runners have an advantage for whatever reason, then this has the potential to affect their performance negatively, especially if this belief is being supported by peers and social constructs. Clearly this may result in the formation of a self fulfilling prophecy.

Finally, it is important to consider the factors to which individuals attribute their successes and failures. Gill ${ }^{17}$ describes the attribution of failure to stable external factors-for example, task difficulty, better opponents - as reducing the shame associated with failure, but as having the worst prognosis for future performance. Understandably, this is the process caucasian runners may use whenever looking for a genetic, developmental or physiological advantage in being East African. In comparison, East Africans may now believe that they have physiological advantages that explain their success. This stable internal attribution style will have a positive effect on their future performance.

It is clear that there is a theoretical rationale that psychology plays a critical role in the dominance of the East African runner. The attitudes of both the African and caucasian may be providing an advantage as great as, or greater than, any of the more tangible factors more traditionally studied.

\section{Conclusions}

Domination of individual sports by countries or regions of the world is not a new phenomenon. It seems that the presumed causes of such domination are often recycled, out of date, and based on misinformation and myth. Over the last few years, it appears that North African countries have been producing large numbers of elite international athletes. Are we now going to search for the genetic advantages of these nations? Although there is no conclusive evidence for an inherited physiological advantage to the East African, this does not exclude the possibility that one actually does exist. It may be that the technology required to detect any differences is currently lacking.

However, irrespective of the existence or otherwise of any physiological advantage, it is possible that the attribution of caucasian running "failures" to anecdotal stable external factors disempowers caucasians. Similarly, this attribution style empowers the East African, just as it did the Scandinavians in the early 20th century and Australasians in the 1950s and 1960 s, with a psychological advantage, the importance of which cannot be overestimated. Fixed beliefs and attitudes to those anecdotal contributory factors continue to impede the success of caucasian athletes. Sports scientists and practitioners aim to maximise athletic performance, and yet it seems that they are all too ready to accept that the East African dominance is due to factors out of their control. Although many factors contribute to East African running success, present caucasian belief 
and attitude systems may be a significant perpetuating influence. Until our athletes, coaches, and support staff accept responsibility for their own performance, the current level of athletic domination by East African athletes may continue.

I would like to thank Professor Peter Fricker and Dr Kim Bunnell for their support and assistance in the preparation of the manuscript.

1 Hoberman J. Darwin's athletes. How sport has damaged black america and preserved the myth of race. 1st ed. New York: Houghton Mifflin Company, 1997.

2 Hurst M. Running: Not a black and white issue. Fun Runner 1995:24-6.

3 Saltin B, Terrados N, Larsen H, et al. Morphology, enzyme activities and buffer capacity in leg muscles of Kenyan and Scandinavian runners. Scand $\mathcal{F}$ Med Sci Sports 1995;5:22230.

4 Cobb WM. Race and runners. Fournal of Health and Physical Education 1936 Jan:3-56.

5 Bale J, Sang J. Kenyan running. Movement culture, geography and global change. 1st ed. London: Frank Cass and Co Ltd, and glob.

6 Rosser BWC, Hochachka PW. Metabolic capacity of muscle fibers from high-altitude natives. Eur $\mathcal{f}$ Appl Physio fibers from high

\section{Take home message}

The periodic domination of middle and long distance running by different regions of the world is not a new phenomenon. Researchers are yet to confirm a genetic or physiological advantage in being a middle or long distance runner of East African origin, and it is most likely that the reasons for their success are many. The belief that East African success is due to uncontrollable stable factors will perpetuate the current level of domination.
7 Kayser B, Hoppeler H, Claassen H, et al. Muscle structure and performance capacity of Himalayan Sherpas. $\mathcal{F}$ Appl Physiol 1991;70:1938-42.

8 Noakes T. Maximal oxygen uptake: "classical” versus "conemporary" viewpoints: a rebuttal. Med Sci Sports Exerc 1998;30:1381-98.

9 Lenton B. Off the record. Collectors edition. Duffy: Brian Lenton Publications, 1981.

10 Saltin B, Larsen $\mathrm{H}$, Terrados $\mathrm{N}$, et al. Aerobic exercise capacity at sea level and at altitude in Kenyan boys, junior and senior runners compared with Scandinavian runners. Scand 7 Med Sci Sports 1995;5:209-21.

11 Weston AR, Karamizrak O, Smith A, et al. African runners exhibit greater fatigue resistance, lower lactate accumulation, and higher oxidative enzyme activity. F Appl Physiol 1999;86:915-23.

12 Coetzer P, Noakes TD, Sanders B, et al. Superior fatigue resistance of elite black South African distance runners. $\mathcal{F}$ Appl Physiol 1993;75:1822-7.

13 Andrews H. Training for the track, field and road with some hints on health and fitness. 1st ed. London: Stanley Paul and Co, 1920.

14 Kosgei M, Abmayr W. Cross country training in Kenya. New Studies in Athletics 1988;4:53-9.

15 Iso-Ahola SE. Intrapersonal and interpersonal factors in 9 .

16 Mahlmann P. Perception of sport in Kenya. fournal of Eastern African Research and Development 1989;19:119-45.

17 Gill DL. Psychological dynamics of sport. Champaign, IL: Human Kinetics Publishers, Inc, 1986. 